\title{
Investigating Social Media Utilization and Challenges in the Governmental Sector for Crisis Events
}

\author{
The case of Saudi Arabia
}

\author{
Waleed Afandi \\ Management Information System Department \\ College of Business in Rabigh \\ King Abdulaziz University \\ Saudi Arabia
}

\begin{abstract}
The use and utilization of social media applications, tools, and services enables advanced services in daily routines, activities, and work environments. Nowadays, disconnection from social media services is a disadvantage due to their increasing use and functionality. The use of social media applications and services has provided different methods and routines for communications that ranges from posting, reposting, commenting, interacting, and live communication that can reach a mass population with minimum time, effort, and expenses compared with traditional media systems and channels. The current benefits of using social media can assist in providing better services in terms of communication and guidance for civil protection services within governmental sectors, as reported by different research studies. The use of social media has been found to be critically important by governmental agencies in different situations for directing, educating, and engaging people during different events. This study investigates the use of social media services in Saudi Arabia in governmental sectors to outline the opportunities and challenges faced, given the challenging situations faced annually during the Hajj and Ramadan rituals, and sporadic flood crisis events. This research focuses on defining the current stand and challenges of using social media services for providing mass communication and civil engagement during hazardous and challenging events in Saudi Arabia. The results of this study will be used as a roadmap for future investigation in this regard.
\end{abstract}

Keywords-Component; civil protection; hajj; social media; Saudi Arabia; governmental sector; flood crisis

\section{INTRODUCTION}

Nowadays, many governmental sectors are seeking to enhance their services through providing direct communication with the public via e-government facilities. Engaging the public in timely communication can provide faster and more responsive services, and better engagement, solving problems and providing better governmental services. Moreover, in the cases of unordinary events, the need for having timely and interactive communication is essential to mitigate hazards, guide people, and be informative concerning the situation. Different governmental authorities worldwide have realized the potentials of using these services in providing better far superior means of communication than traditional communications systems for general use or those for emergencies and hazardous events.
The use of traditional communication systems is inefficient and does not provide engagement for active communication with the public. With the advent of mass internet usage since the 1990s, different solutions embodying the use of social media systems have been utilized by official agencies during extraordinary events to overcome the problems of traditional communication systems and go beyond their abilities in providing real-time communication channels, employed for sharing valuable government-to-citizen and citizen-to-citizen information among users.

The rites associated with Hajj and Ramadan, particularly religious rituals for Muslim pilgrims from all over the world in the former, are considered one of the main challenges facing governmental sectors in the Kingdom of Saudi Arabia (KSA). Hajj is considered the oldest continuing mass gathering, with an average of three million people converging on the same area and performing the same rituals [1]. The high population density of 8-9 persons per square meter has resulted in frequent stampedes that have posed critical emergencies on many occasions, resulting in deaths and serious injuries. Moreover, different challenges such as fire, terrorism, and health issues have been reported during the Hajj [2]. Controlling and guiding such large masses of with traditional communication systems is impossible, especially as pilgrims are coming from different countries with diversity in ethnic origins and languages.

Other crisis events that have been reported in different locations in KSA include as man-made events and natural disasters, including epidemics, flooding, fire, and chemical and ecological impacts) [3]. In order to enhance preparedness for such events, including crisis mitigation and early resilience efforts against emergencies, the inclusion of social media services in government communication offers promising potential, as reported in many research studies. Using social media for strengthening the relations with governmental, local, and regional participants, including communities, is vital for mitigating the effects of and controlling the responses to situations concerning public behavior, through active communication and engagement [4].

The results of this research study provide a benchmark defining the challenges and changes in utilizing social media services among governmental sectors in KSA. Moreover, they assist in defining the main barriers and opportunities for engaging social media services during critical events. This 
research contributes to filling the gap in the literature and provides awareness of the current situation and practices prior to implementing any future solutions. The following sections will introduce the used methodology and survey that was created, tested and used for investigating the current situation and stand toward the effective use of social media during crisis events in Saudi Arabia.

The aim and importance of this study is to investigate the current use of social media services in Saudi Arabia in governmental sectors, to be able to outline the opportunities and challenges faced, given the challenging situations faced annually during the Hajj and Ramadan rituals, and sporadic flood crisis events. Such information is needed prior to providing any solution that might be proposed in the future for mitigating the effects of crisis events and emergencies using social media technologies.

\section{MethodOLOGY}

This study investigates the status of social media usage in the governmental sectors involved with critical events and emergencies in KSA, and defines the challenges and opportunities facing future use. As no substantive information is available from previous studies or official reports concerning the subject of concern, this research deploys quantitative methods, through distributing a questionnaire to explore the uses of social media in critical events.

A list of 23 ministries in KSA was obtained, 13 of which were officially contacted as their work and responsibilities were identified with relevance to: (1) critical and emergency events, and (2) mass public interest, as shown in Table I.

Each ministry was contacted with an official letter explaining the purpose and importance of this research, and the benefits that may result from their cooperation. All of the approached ministries agreed to take part in this research study, and this agreement was used to contact different governmental agencies to investigate each ministry's operations. Each ministry has numerous directories, authorities, councils, chambers, and commissions. Those governmental entities were identified through visiting the official web sites of each ministry, and they were contacted via email with a questionnaire attached in April 2017 for the purpose of this research study, representing a total of 53 entities. The participation importance of those governmental entities was accentuated, as the result is believed to fill the gap in literature as well as helping in creating a better understanding for future services and operations, with recommendations for improvements in preparedness for and response to crisis and emergency events. The importance of this study lies in addressing a critical gap in literature (concerning e-government in KSA in genera), as well as assisting in the creation of a better understanding and future recommendations for using social media in crisis management.

The questionnaire used for this research had a mixture of open-ended and closed questions derived from major research studies in this field [5-7]. They were adapted to suite the particular purposes and scope of this research, focusing on Saudi governmental agencies.
TABLE. I. SAUDi MinistriEs INVESTIGATED

\begin{tabular}{|l|l|}
\hline No. & Ministries \\
\hline 1 & Civil Services \\
\hline 2 & Communication and Information Technology \\
\hline 3 & Education \\
\hline 4 & Higher Education \\
\hline 5 & Foreign Affairs \\
\hline 6 & Hajj \\
\hline 7 & Health \\
\hline 8 & Interior \\
\hline 9 & Labor \\
\hline 10 & Municipal and Rural Affairs \\
\hline 11 & Social Affairs \\
\hline 12 & Water and Electricity \\
\hline 13 & Transport \\
\hline
\end{tabular}

The close-ended questions were analyzed based on frequency using MS Excel. The open-ended questions were provided to have better understanding and description of the challenges. The answers were collected and coded using a coding frame based on $25 \%$ of total participants. NVivo 7.0 was used for providing the coding and defining nodes, used to derive relationships and provide themes identified from answers to each question used in the questionnaire. The statistical significance of the used questionnaire is indicated by a $93 \%$ confidence level, with a difference of (+/- 5) between responses. Responses to open-ended questions are considered indicative.

The final responses analyzed from the studied governmental agencies came from 23 respondents who completed the questionnaire (a response rate of 43\%). It is believed that the results from this research are significant as many governmental agencies who participated voluntarily were grouped to identify the common challenges they face, and to fill the gap in literature towards social media usage during crisis events. The governmental participants were informed that the data of this research will be used for research purposes only, and the results of this study will be shared with them.

\section{FINDINGS OF THE STUDY}

The results offered in this paper are just a part of a larger research investigation carried out concerning governmental entities' utilization of social media services in KSA. The focus in this stage is related towards defining the status and outlining the challenges of using social media by governmental entities in KSA. The following sections present the outcomes relevant to the current investigation.

\section{A. Governmental Entities' Utilization of Social Media}

Fig. 1 shows the results obtained from governmental entities on their current official utilization of social media services with their job responsibilities. The question was (identify your current position with using social media towards public services and communication).

The results came from a closed-ended question, and they indicate that most $(62 \%)$ participating governmental entities in this study answered (we decided not to use it). The results show that those entities have been introduced to social media 
usage, and for some reasons that will be identified later in this study, they decided not to consider using it. This large percent shows a real concern towards choosing not to use social media services. The second highest percent $(27 \%)$ was for the option of (we are planning to use it in the near future). This result shows that there is still a good level of receptiveness among governmental entities towards using social media services; the upcoming results define the driving forces for using social media services. The third highest percent $(8 \%)$ was related to the answer of (we are using social media occasionally). It was found from content analysis methodology of the visited social media pages that $94 \%$ of pages are unidirectional in providing interactive communication with public, and they are mainly used for announcing information only. The same governmental attitude has been reported by a previous research study [8], which showed that within a period of three years no change has been found in governmental employees' attitudes towards using social media with the public. The last option of (we didn't consider using it) was selected by only $4 \%$. The results show that those governmental agencies have not been introduced to the benefits or possibilities of using social media, and they are not aware of how to merge social media services with their governmental operations in communicating with the public.

The next question in this study was related to identifying the reasons for not using social media services within governmental entities' operations towards the public. The results are shown in Fig. 2.

The answers came from an open-ended question, and coding technique was performed to identify themes through the keywords repeated in participants' answers, known as nodes. The results show that the most commonly cited rationale for not adopting social media was related to (security issues) $(42 \%)$. Security concerns have been reported in different studies related to social media use and are a main concern among different adopters of social media services [9-11]. Close behind this, the second-highest percentage (39\%) selected (technical challenges). The nodes defined from participants' answers are shown in Table II.

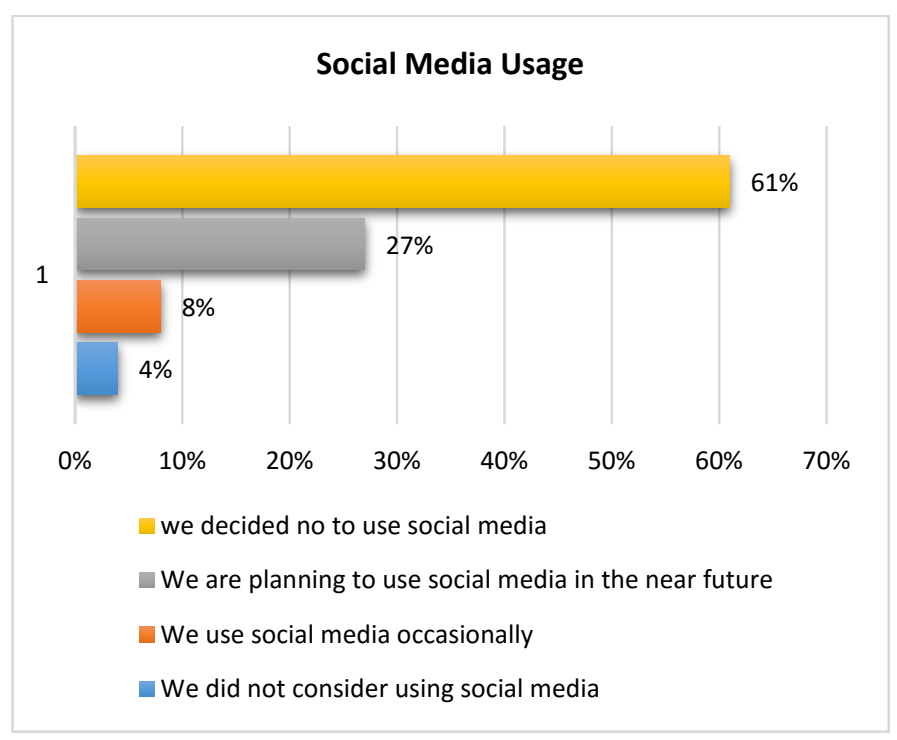

Fig. 1. Social Media usage in Saudi Governmental Entities.

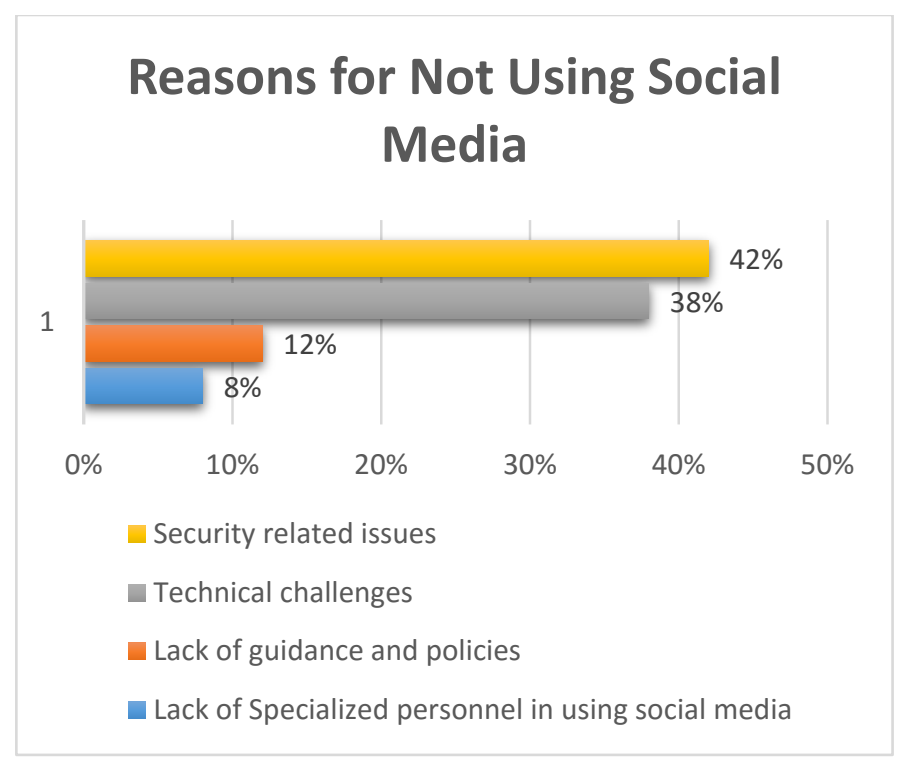

Fig. 2. Factors Affecting Social Media Adoption.

TABLE. II. DEFINED TeChNICAL CHALLENGES

\begin{tabular}{|l|l|l|}
\hline & Technical Challenges & $83 \%$ \\
\hline 1 & Managing multiple accounts & $67 \%$ \\
\hline 2 & Managing response to public & $24 \%$ \\
\hline 3 & Staying compliant & \\
\hline
\end{tabular}

It can be seen from Table II that (managing multiple accounts) on different social media services is considered the main challenge for governmental entities in KSA by a large majority of participants (83\%). This is related to the two points defined in Fig. 2 (lack of guidance and policies, lack of specialized personnel). However, this issue can be resolved by using social media management tools that are capable of managing different social media services and accounts from one portal or interface $[11,12]$. The second-highest percentage (67\%) was related to (managing responses to the public), and this issue can also be resolved by using social media management tools and trained and dedicated personnel working specifically with social media tools and services. The last technical challenge in this category is related to (Staying compliant), cited by almost a quarter (24\%) of participants. This can be resolved through having dedicated training and policies for the staff managing social media services.

Going back to the reasons outlined as challenges towards using social media, it was found that the third-highest percent (12\%) of total answers was related to (lack of guidance and policies). Having guidance and policies can be a critical factor for social media sustainability in governmental entities' operations and services. Different research studies have emphasized the importance of having well-documented and verified guidelines and policies for guiding staff on the use of social media services [12-15]. The last challenge in this category is related to (lack of specialized personnel) (8\%). Having specialized personnel is seen as critical necessity, especially in the cases of crisis events or sensitive governmental entities, as people can rely on what is posted on those social media pages [16]. Most of the previous stated 
challenges have been found in previous research studies, and it is evident that KSA governmental entities can learn from previous experiences through enhancing employee knowledge by revising the literature and following the solutions and recommendations of different research outcomes.

\section{B. Ownership of Social Media within Governmental Agencies}

This section investigated participants' responses on the driving forces for using social media services within their governmental entities' responsibilities and operations. The question was open-ended, and the following responses were outlined (Fig. 3).

The results show that the largest answer (32\%) was (ensuring better communication with the community). The literature emphasizes the benefits of using social media for having better communication with the public [4, 13]. This result shows that the governmental entities are aware of the benefits of social media communication with the public in KSA. A close second was (enhancing services) (28\%). This is closely related to the former point, as it is believed that social media can enhance the services of governmental sectors towards the public. The third highest percent (21\%) was achieved by (benefits of the technology). Relating this to previous answers in this research study, it is evident that Saudi officials are aware of the benefits of social media technology, but lack of guidelines, policies, and specialized personnel, which is a major challenge to effectively adopting and using such tools. The fourth highest percent $(15 \%)$ is related to (specialized staff), and it shows that there is a need for specialized staff that have deep knowledge in the field of using social media services and tools in e-government applications; basic knowledge or amateur experience cannot be relied on in such sensitive governmental entities' operations and tasks. The last answer for the provided question was (other governmental entities use) (4\%). Although this result is minimal, it shows that some governmental entities can be affected and encouraged by the successful use of social media by others [17].

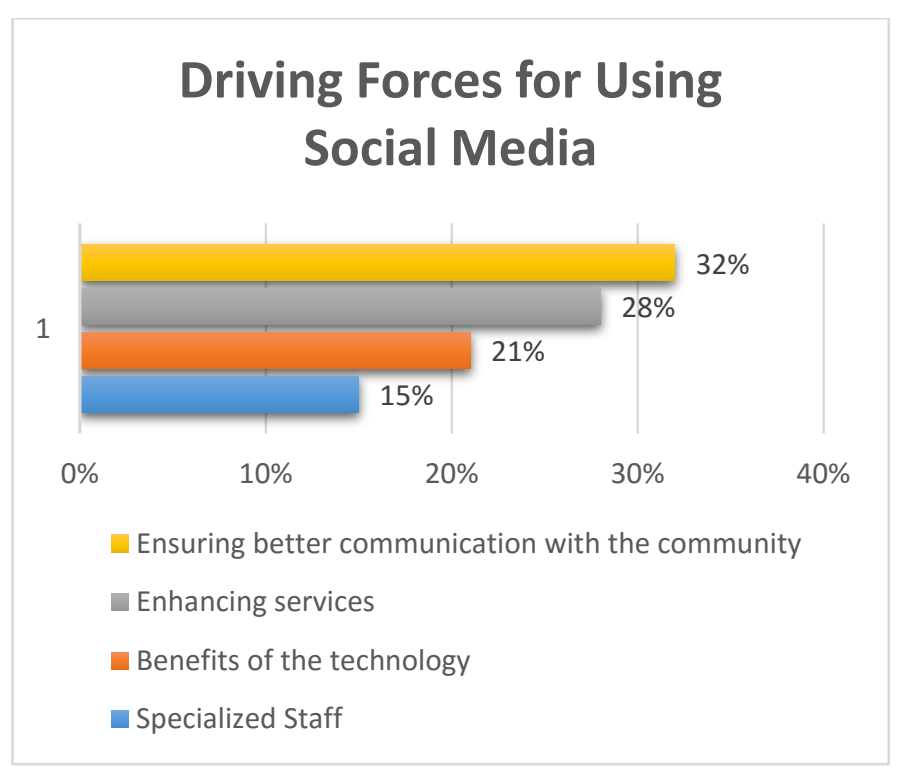

Fig. 3. Driving Forces for using Social Media.
The previous driving forces have been related to the case of KSA governmental entities. However, different driving forces can be outlined for adopting social media services within governmental entities, as some driving forces are similar to the ones defined in this study, as all depend on the intentions of use, position, and sensitivity of services and operations [5, 9].

Many research studies demonstrated that social media influences how the public anticipate crises through the reactions that they feel when exposed to crisis information [18]. Moreover, organizations like the Red Cross and Federal Emergency Management Agency (FEMA) have depended heavily on using social media for communicating with the public during crisis events, to manage and coordinate their own activities in addition to helping the public per se. For example, in 2009 the U.S. Army used social media services to update the public on the Fort Hood Shootings. In the same manner, the Red Cross uses social media services to communicate with the public regarding potential crisis. During the Virginia Tech shooting in 2007, the public used and interacted with social media services, as well as in the incidents of California wildfires, wherein the public pursued information from social media services, as they felt that traditional media sources were too general or imprecise [19]. The previous incidents show that communicating with the public in a wider scope using social media is its main advantage from a government services perspective, for all governmental entities or organizations involved in mass public communication and crisis events.

\section{The Use of Social Media Policy}

The study investigated the option of using social media policies by governmental entities in KSA with the close-ended question (does your organization have a social media policy?). The results obtained are shown in Fig. 4.

The results show that the great majority of Saudi governmental entities do not have social media policy $(83 \%)$. (Currently developing) was selected by $13 \%$, while only $4 \%$ declared that they have a policy for using social media. Social media policies can be issues with respect to governmental entities' nature of services and operations. Thus, many different social media policies can be developed. Many benefits are expected from having such policies, as adumbrated below [20, 21].

\section{Status of Social Media Policy}

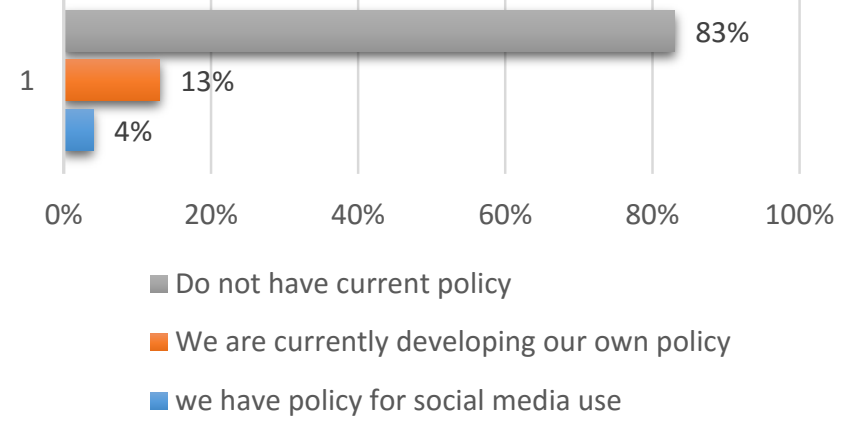

Fig. 4. Using Social Media Policy. 
1) Identifying services' scope

2) Protecting organizational reputation

3) Managing against rumors

4) Raising awareness of governmental operations

5) Defining confidential and private information

6) Defining the official voice responsible in the organization

7) Defining the proper way to engage with public and other governmental entities

8) Educating and training employees

9) Removing confusion about legal matters

Using social media policies can be critical in many cases, especially in times of crisis and risk events. Thus, special consideration should be given towards establishing policies that go along with governmental entities' particular services, operations, and expected crisis events. The current practice of having many governmental entities using one general policy can jeopardize the use of social media, as such policies need to be more specific and oriented towards the governmental entities' work and services [22].

\section{Adoption Stage for Social Media}

The adoption process for social media in governmental entities has to come into three different stages [22]:

1) Entrepreneurship and experimentation

2) Constructive chaos

3) Institutionalization

Based on the previous stages, adopting social media by governmental entities starts by informal experimentation with social media outside of the used technological use policies. In the second stage, an order develops from the first disordered stage, as governmental entities recognize the need to draft rules, policies, and guidelines. The final stage consists of formalizing social media strategies and policies in terms of proper performance, types of engagements, and new modes of communication [22].

According to the previous definition of adoption stages, and based on the findings in this research study, it is to be concluded that many KSA governmental entities are classified in the (entrepreneurship and experimentation) stage, for nonadaptors of social media services, and in the (constructive chaos) stage for the governmental entities that have tentatively adopted social media services.

In order to develop the practices into the third stage, Saudi governmental agencies need to address the challenges defined in this study and work on forming dedicated policies with respect to each governmental entity's work, services, and operations.

\section{CONCLUSIONS}

This paper investigated the current status of using social media services in governmental entities in KSA. The results showed that most governmental entities are not active in using those services towards promoting better services to the public or during crisis events. Different obstacles and challenges have been identified that warrant more consideration and planning to overcome the current status of a lack of or ineffective use of social media facilities. The literature related to social media usage in crisis events is full of different successful cases where social media services were adopted and helped during the different stages of crises events. In many cases, social media played critical role that served to save thousands of lives and promote better cooperation between the governmental entities and the public. Those cases should be introduced and considered by Saudi governmental entities by dedicated experts, to help in reforming the norms and regulations of use. However, despite the current low adoption of social media services, this research managed to outline the opportunities for better future utilization, and showed the current status of the use of such services in cases of crisis events and emergencies. Most Saudi governmental entities have been defined in stage 1 and 2 of the presented adoption stages previously presented in this research, and with a proper consideration of challenges, it is believed that Saudi governmental entities can make good use of social media services that can promote better services among governmental entities themselves, and with the public, including during Hajj, Ramadan rituals, and crisis events and emergencies. The future work associated with this research will be to create a framework that will enable different governmental and public entities to collaborate and share defined and structured policies for better cooperation among themselves in order to mitigate the impact of crisis events and emergencies using effective social media technologies.

\section{ACKNOWLEDGEMENT}

This project was funded by the Deanship of Scientific Research (DSR) at King Abdulaziz University, Jeddah, under grant no. G: 1385-849-1440. The author, therefore, acknowledge with thanks DSR for technical and financial support.

\section{REFERENCES}

[1] S. Yezli, B. M. Alotaibi, and A. A. Bin Saeed, "The Hajj health tequirements: time for a serious review?" The Lancet, vol. 387, no. 10021, pp. 845-846, 2016.

[2] A. Shujaa, and S. Alhamid, "Health response to Hajj mass gathering from emergency perspective, narrative review," Turkish Journal of Emergency Medicine, vo. 15, no. 4, pp. 172-176, 2015.

[3] E. Tambo, A. M. Fouad, and E. I. M. Khater, "Strengthening community emergency preparedness and response in threats and epidemics disasters prevention and management in Saudi Arabia," International Journal of Emergency Management, vol. 13, no. 3, pp. 288-303, 2017.

[4] S. Matar, N. Matar, W. Balachandran, and Z. Hunaiti, "Social media platforms and its application in natural disaster and crisis events: The case of Bosnia and Herzegovina," Information and Knowledge Management Journal, vol. 6, no. 5, pp. 50-56, 2016.

[5] Š. A. W. Matar, "Enhancing situational awareness and communication during flood crisis events using social media framework: the case of Bosnia and Herzegovina," doctoral dissertation, Brunel University London, 2017.

[6] Alharbi, N., "The impact of using YouTube on crisis communication during Jeddah floods in 2009 and 2011," doctoral dissertation, Bowie State University, 2015.

[7] UN OCHA, "Examples of coordination challenges," 2013. retrieved March 92013 from http://www.humanitarianresponse.info/en/system /files/documents/files/OCHA_Some Examples of Coordination Challenges.pdf.

[8] Y. Al-Saggaf, and P. Simmons, "Social media in Saudi Arabia: Exploring its use during two natural disasters," Technological Forecasting and Social Change, vol. 95, pp. 3-15, 2015. 
[9] K. Njenga, "Social media information security threats: Anthropomorphic emoji analysis on social engineering," IT Convergence and Security 2017, 2018, pp. 185-192. Springer, Singapore.

[10] J. Kim, and M. Hastak, "Online human behaviors on social media during disaster responses," Journal of the NPS Center for Homeland Defense and Security, vol. 13, pp. 7-8, 2018.

[11] B. Tadic, M. Rohde, and V. Wulf, "CyberActivist: Tool for raising awareness on privacy and security of social media use for activists," International Conference on Social Computing and Social Media, Cham, Switzerland: Springer, July 2018, pp. 498-510.

[12] L. Ngamassi, A. Malik, J. Zhang, and D. Ebert, "Social media visual analytic toolkits for disaster management: a review of the literature," Proceedings of the 14th International Conference on Information Systems for Crisis Response and Management (ISCRAM), Albi, France, 2017, pp. 49-54.

[13] C. Reuter, and M. A. Kaufhold, "Fifteen years of social media in emergencies: A retrospective review and future directions for crisis informatics," Journal of Contingencies and Crisis Management, vol. 26, no. 1, pp. 41-57, 2018.

[14] C. Stohl, M. Etter, S. Banghart, and D. Woo, "Social media policies: Implications for contemporary notions of corporate social responsibility," Journal of Business Ethics, vol. 142, no. 3, pp. 413-436, 2017.

[15] D. Walster, "Information policy and social media: Accept or decline," TechTrends, vol. 61, no. 3, pp. 301-307, 2017.
[16] M. L. Jibril, I. A. Mohammed, and A. Yakubu, "Social media analytics driven counterterrorism tool to improve intelligence gathering towards combating terrorism in Nigeria," Ideas, vol. 107, pp. 33-42, 2017.

[17] A. Haro-de-Rosario, A., Sáez-Martín, and M. del Carmen Caba-Pérez, "Using social media to enhance citizen engagement with local government: Twitter or Facebook?" New Media and Society, vol. 20, no. 1, pp. 29-49, 2018.

[18] Y. Jin, B. F. Liu, and L. L. Austin, "Examining the role of social media in effective crisis management: The effects of crisis origin, information form, and source on publics' crisis responses," Communication Research, vol. 41, no. 1, pp. 74-94, 2014.

[19] J. B. Houston, J. Hawthorne, M. F. Perreault, E. H. Park, M. Goldstein Hode, M. R. Halliwell, S. E. Turner McGowen, R. Davis, S. Vaid, J. A. McElderry, and S. A. Griffith, "Social media and disasters: A functional framework for social media use in disaster planning, response, and research," Disasters, vol. 39, no. 1, pp. 1-22, 2015.

[20] J. C. Bertot, P. T. Jaeger, and D. Hansen, "The impact of polices on government social media usage: Issues, challenges, and recommendations," Government Information Quarterly, vol. 29, no. 1, pp. 30-40, 2012.

[21] M. W. DiStaso, T. McCorkindale, and D. K. Wright, "How public relations executives perceive and measure the impact of social media in their organizations," Public Relations Review, vol. 37, no. 3, pp. $325-$ $328,2011$.

[22] I. Mergel, and S. I. Bretschneider, "A three-stage adoption process for social media use in government," Public Administration Review, vol. 73, no. 3, pp. 390-400, 2013. 